\title{
ALEJANDRO VERGARA BLANCO, DERECHO DE AGUAS, SANTIAGO DE CHILE, EDITORIAL JURÍDICA, 1998, 548 PP.
}

\section{Christian Rojas Calderón (iD}

El trabajo académico que ha desarrollado el profesor Dr. Alejandro Vergara Blanco, Profesor de Derecho de Aguas y de Derecho de Minas de la Pontificia Universidad Católica de Chile, se ha manifestado, a través del tiempo, en un área que constituye una unidad constituida por el Derecho Administrativo, el Derecho de Minas y el Derecho de Aguas.

En esta última área específica, el Profesor Vergara Blanco había publicado en diversas sedes y en los últimos años, distintos trabajos acerca del tema que corresponde a esta reseña. Sin embargo, entre todos aquellos existía un hilo conductor que hoy se ha materializado en esta completísima obra.

Aun cuando el mismo Profesor Vergara señala en el Prefacio (pp. 9-10) que esta obra constituye una recopilación de trabajos publicados en diversas revistas, o correspondientes a ponencias realizadas en congresos en Chile y en el extranjero, se reafirma la idea recién planteada, lo que se hace evidente en la obra en general. trabajo.

No obstante ello, es posible realizar algunas distinciones en la estructura de este

Una primera parte, que comprende los Capítulos 1ro. al 6to., importa una reconstrucción histórico-jurídica del Derecho de Aguas. Una segunda parte, que comprende los Capítulos $7 \mathrm{mo}$. al 9 no., que constituye el análisis de los principios que rigen nuestro actual Derecho de Aguas. Finalmente, una tercera parte, que comprende los Capítulo $10 \mathrm{mo}$. al 16 to., y que corresponden al análisis de problemas prácticos, quizás los más relevantes que se plantean en materia de aguas.

Como quizás nos tenga acostumbrados, el autor va más allá de los estrictos límites del análisis horizontal de la materia en estudio, y se embarca hacia un análisis vertical del objeto, pues argumenta sobre la base de la historia, de la dogmática y de la práctica, lo que constituye, sin duda alguna, una novedad dentro de nuestra reposada literatura jurídica.

La obra del Profesor Vergara comienza con una introducción general en la que ensaya un análisis del "Derecho de Aguas ante la historia y la legislación vigente" (pp. 11 a 25), en la cual explica la necesidad imperiosa, a mi modo de ver, de realizar un estudio de la disciplina en los términos que se plantea en esta obra. Establece además los objetivos de la investigación, que consisten esencialmente, al menos en su primera parte, en develar la "historia institucional del Derecho de Aguas a través de un estudio retrospectivo de todos los textos jurídicos que sirven de antecedente a nuestra actual legislación de aguas". A partir de este razonamiento, primero se realizará la reconstrucción histórica, para luego efectuar la reconstrucción dogmática del Derecho de Aguas. 
Luego, el autor presenta sus hipótesis de trabajo, que constituyen y contienen, a su vez, las características, principios e instituciones del Derecho de Aguas, a saber: un dominio público de las aguas, un procedimiento concesional para el otorgamiento de derechos sobre las aguas, derechos reales administrativos de aprovechamiento sobre las mismas, e intervención administrativa de las aguas.

Finalmente, luego de presentar la bibliografía más relevante a usar y los objetivos específicos del estudio, ensaya lo que denomina "Núcleo dogmático del Derecho de Aguas", a partir de los textos vigentes en materia de aguas, como son la Constitución Política, el Decreto Ley №2.603, de 1979, y el actual Código de Aguas, en los cuales reconoce la presencia de los pilares señalados, que importan al mismo tiempo, sus hipótesis de trabajo.

La primera parte de la obra comprende la "Historia del Derecho de Aguas", la que se encuentra dividida, a su vez, en seis capítulos, en cada uno de los cuales ensaya con éxito, sin duda, la presencia de sus hipótesis- pilares del Derecho de Aguas.

El capítulo primero, "Fuentes del Derecho Romano de Aguas" (pp. 29 a 44), pasa revista al dominio y aprovechamiento de las aguas, analizando los textos correspondientes al derecho romano clásico, y luego hace lo mismo en el derecho romano post clásico.

El capitulo segundo, "Fuentes y principios del Derecho Español Medieval de Aguas" (pp. 45 a 82), comienza analizando el concepto de regalía, que luego funda nuestro actual dominio público y que nace precisamente en esa época. Posteriormente, analiza esta figura en los textos hispánicos de las leyes correspondientes a las Cortés de Nájera, de 1138, al Fuero Juzgo y a Las Siete Partidas. En ellas, se detiene y analiza los ya evolucionados derechos patrimoniales de los reyes u sus caracteristicas, vigentes hasta hoy, así también como la condición jurídica de las aguas, revisando el dominio sobre las mismas, los otorgamientos reales (hoy concesiones) y los derechos de uso. Finalmente, revisa el Ordenamiento de Alcalá.

El capítulo tercero, de las "Fuentes y principios del Derecho Español Moderno y Decimonónico de Aguas", analiza en su primera parte, del Derecho Moderno de Aguas, el asentamiento de los instrumentos jurídicos en la legislación, a saber: las Ordenanzas Reales de Castilla, la Nueva Recopilación y la Novísima Recopilación, estableciendo un paralelo entre los textos para dar cuenta de su interpolación. En su segunda parte, del Derecho Español Decimonónico, para revista a la Ley de Aguas Española de 1879, importante no sólo por su pervivencia en la península (rigió hasta 1985), sino también por su influencia en la posterior codificación del Derecho de Aguas en Chile.

El capítulo cuarto, "Fuentes y principios del Derecho Indiano de Aguas" (pp. 98 a 127), expone los textos indianos en la materia, pero ya no aisladamente, sino a través del reconocimiento de usos y principios generales, conforme a los cuales se desenvolvería el Derecho de Indias, para luego pasar a revisar las Mercedes de Aguas, especialmente su concepto, los derechos de Uso y Aprovechamiento y la Intervención Administrativa.

Con el capítulo quinto, de las "Fuentes y principios del Derecho Contemporáneo de Aguas" (pp. 128 a 191), revisa la legislación nacional de aguas desde sus primeras manifestaciones. Así, distingue una primera parte, precodificada, de Derecho Nacional de Aguas antes del Código Civil, para luego en el Código Civil, desde 1857 hasta fin de 
siglo, en la que se analizan leyes, códigos y finalmente ordenanzas sobre las aguas, materia última en la cual se pasa revista sólo a algunas ordenanzas; finalmente, se revisa la legislación de aguas desde principios de siglo hasta antes de la codificación. Al concluir este viaje, se llegan a establecer ciertos principios fundantes de la legislación precodificada, a saber: un dominio público de las aguas, un procedimiento concesional a través de las mercedes de aguas, unos derechos de uso o aprovechamiento de las mismas y la intervención administrativa. Luego en su segunda parte, de Derecho de Aguas codificado, pasa revista al Código de Aguas de 1951 y sus principios, a la Ley № 16.640 de reforma agraria y el "nuevo" Código de Aguas de 1967, para finalizar con las disposiciones constitucionales y legales desde 1976 a 1980 .

El capítulo sexto, de "Historia de la codificación del Derecho de Aguas" (pp. 192 a 236), revisa los proyectos de codificación, desde los proyectos de Código Rural de José Victorino Lastarria, pasando por los primeros proyectos de Código de Aguas, con la labor de Rafael Moreno Echavarría, llevándonos a las discusiones parlamentarias, vetos presidenciales y, finalmente, puesta en vigencia del Código de Aguas a través de la Ley N 9.909 de 1951.

La segunda parte de esta obra comprende los "Principios del Derecho de Aguas Vigente", en la cual se analizan dos principios fundantes de nuestra actual legislación.

El primero de ellos, expuesto en el capítulo séptimo, es "El principio de la Unidad de la Corriente en el Derecho de Aguas" (pp. 239 a 256), que indaga sobre la consagración, aplicación e importancia de este elemento directriz que informa toda la legislación de aguas, visitándolo en sus diversos aspectos, como son la hidrología, la historia legislativa y sus implicancias jurídicas, en especial, el seccionamiento de los ríos y el manejo integrado de cuencas.

El segundo, tratado en el capítulo octavo bajo el título de "El principio de la Libre Transferibilidad de los Derechos de Aguas" (pp. 257 a 293), describe la principal característica del Derecho de Aguas chileno a partir de los textos vigentes, cual es la introducción de la libertad de acceso a la creación y libre transferibilidad de los derechos de aguas. Aquello lo realiza a través de una descomposición histórica y luego económica del "mercado de aguas", para luego revisar el sistema vigente y finalmente describir los principales obstáculos y facilidades del sistema de transferibilidad de derechos de aguas o sistema de mercado de aguas, no quedándose en ello solamente, sino que también planteando soluciones a los diversos problemas que surgen de un imperfecto sistema de mercado hídrico.

En la tercera parte de esta obra, denominada "Dogmática del Derecho de Aguas vigente", que se encuentra, a su vez, dividida en cuatro capítulos, analiza la estructura y los problemas más relevantes planteados a partir del encuentro del Derecho con los hechos.

En el capítulo noveno, denominado "Estatuto jurídico, tipología y problemas actuales de los derechos de aprovechamiento de aguas, en especial de su regularización y catastro" (pp. 307 a 363), se constituye quizás como el más importante de los capítulos en toda su obra, puesto que analiza de manera preclara, en virtud del estudio y clasificación que realiza, los diversos derechos de aprovechamiento de aguas, los "constituidos" y los "reconocidos". Para concluir, analiza los principales obstáculos provenientes de la falta de formalización, regularización y catastro de los derechos de aguas. 
El capítulo décimo pasa revista al "Régimen de unidad de la medida de los Derechos de Aguas. Su esencial conexión con la distribución de aguas superficiales" (pp. 368 a 409), a través de un análisis histórico del mismo; a continuación realiza una revisión del régimen existente hoy en día en nuestra legislación de aguas, y luego estudia la conexión de la unidad de la medida con la distribución del recurso hídrico.

El capítulo décimo primero, de la "Construcción de Obras Hidroeléctricas y de Riego" (pp. 412 a 441), pasa revista a la necesidad de obras de riego a partir de una consecuente especial geografía nacional, al régimen jurídico de las obras hidroeléctricas y al régimen jurídico de las obras de riego, con especial referencia a la Ley № 18.450 de fomento de la inversión privada en obras de riego y drenaje.

En el capítulo décimo segundo, de la "Constitución de derechos de aprovechamiento de aguas sobre Derrames. El caso de aguas depositadas por un concesionario sanitario en fuentes naturales" (pp. 444 a 469), responde, esencialmente, a la pregunta de quién son las aguas que escurren por las instalaciones sanitarias, esto es, acerca de la titularidad de las mismas, y luego estudia la naturaleza jurídica de los derrames y las consecuencias de la creación de derechos de aprovechamiento sobre aquellos.

El capítulo décimo tercero titulado "Constitución de derechos de aprovechamiento en aguas embalsadas por una central hidroeléctrica" (pp. 470 a 480) responde, esencialmente, a los efectos jurídicos que recaen sobre las aguas embalsadas, asi como a la posibilidad de crear nuevos derechos de aguas a partir de la captación de recursos hídricos que tiene un embalse.

Finalmente, la cuarta parte, denominada "Prospectiva del Derecho de Aguas", actuando como colofón, presenta, no obstante, el estudio más in extenso supra, un análisis de algunos temas pendientes y por resolver, surgidos a propósito de la aplicación durante casi cuatro lustros de esta nueva legislación de aguas.

El capítulo décimo cuarto, intitulado "Entre lo público y privado iquién es el dueño de las aguas?" (pp. 483 a 491), despierta el interés sobre como "los derechos de aguas de los particulares van siendo dotados cada vez más de un estatuto privado, de cierta intangibilidad frente al Estado", y como el Derecho vigente de aguas chileno estructura el nuevo sistema de derechos de agua, señalando sus características principales.

En el capítulo décimo quinto, denominado "Conflictividad judicial sobre los recursos hídricos en un sistema de mercado de Derechos de Agua" (pp. 492 a 500), a partir de un trabajo sobre litigios judiciales en recursos hídricos en Australia, comentándolo, ensaya un análisis sobre la conflictividad judicial en Chile. A partir de ello, realiza un estudio histórico y causal de los conflictos judiciales en esta materia, de particular importancia si tenemos en consideración que rige en nuestro país un sistema de mercado de derechos de aguas.

En fin, el capítulo décimo sexto, titulado "Perfeccionamiento legal del mercado de derechos de aprovechamiento de aguas" (pp. 502 a 513), expone, resumidamente, el fundamento del "mercado de derechos de aguas", los problemas que presenta, así como los necesarios arreglos institucionales destinados a perfeccionar este sistema de mercado de derechos de aprovechamiento de aguas. 
Es destacable en esta obra, por último, una nota final, un índice onomástico, un índice de fuentes citadas y un completísimo índice general, elementos que siempre se deben agradecer al momento de realizar cualquier consulta en un texto, particularmente en éste de tan nutridas fuentes, y que puede transformarse en las más importante obra de consulta en materia de aguas en Chile. 